\title{
Hubungan Keikutsertaan Prolanis (Program Pengelolaan Penyakit Kronis) dengan Tingkat Efikasi Diri Pasien Diabetes Mellitus Tipe 2 di Puskesmas 1 Kembaran
}

\author{
Anindya Widianingtyas ${ }^{1}$, Mustika Ratnaningsih Purbowati², Luhur Dewantoro ${ }^{3}$, Irma \\ Finurina Mustikawati ${ }^{4}$
}

1) Kesehatan Masyarakat, Fakultas Kedokteran, Universitas Muhammadiyah Purwokerto

*Corresponding author: mustikaratnaningsih@gmail.com

\begin{abstract}
Background: Data Sample Registration Survey 2014 showed that diabetes was the thirdlargest cause of death in Indonesia. Diabetes Mellitus which is not promptly treated can lead to the decrease of productivity, disabilities, and early death. Government through Social Health Insurance establishes a Chronic Disease Management Program to handle this case. This activity is expected to increase sufferers' self-efficacy of Diabetes Mellitus Type 2 disease in the medication compliance. Objective: To identify the correlation between the participation of Chronic Disease Management Program and the level of self-efficacy on patients with Diabetes Mellitus type 2 at Puskesmas (Primary Health Care Center) 1 Kembaran. Method: This observational analytic research with cross-sectional involved 44 patients with Diabetes Mellitus type 2 who registered to Chronic Disease Management Program by simple random sampling, the analysis of the data used Spearman correlation test. Results: The results showed that from 44 respondents, the distribution of respondent characteristics was dominated by respondents with the final elderly category 52.3\%, female gender $84.1 \%$, elementary education level 59\%, and unemployment 36,4\%. The results showed that patients of Diabetes Mellitus type 2 who joined Chronic Disease Management Program with low self-efficacy level was 7\%, 7\% patients showed moderate self-efficacy level, and the patients with high level of self-efficacy was $86 \%$. Spearman analysis showed a significant correlation between the participation of Chronic Disease Management Program and the self-efficacy level on patients with Diabetes Mellitus type 2 at Puskesmas (Primary Health Care Center) 1 Kembaran with P value of $0.000(P=<0.05)$. Conclusion: There is a significant correlation between the participation of Chronic Disease Management Program and the level of self-efficacy on patients with Diabetes Mellitus type 2 at Puskesmas (Primary Health Care Center) 1 Kembaran.
\end{abstract}

Keywords: Self Efficacy Level, Prolanis (Chronic Disease Management Program), Diabetes Mellitus Type 2.

\begin{abstract}
ABSTRAK
Latar Belakang: Diabetes mellitus (DM) masih merupakan salah satu penyebab kematian terbesar dalam urutan ke-3 menurut sample registration surver tahun 2014 di Indonesia. DM yang tidak segera ditangani dapat menyebabkan penurunan produktivitas, disabilitas, dan kematian dini. Dalam penanganannya pemerintah melalui BPJS Kesehatan membentuk Program Pengelolaan Penyakit Kronis (Prolanis). Kegiatan Prolanis ini diharapkan mampu
\end{abstract}


meningkatkan efikasi diri penderita DM tipe 2 dalam kepatuhan perawatan penyakitnya. Tujuan: Mengetahui hubungan antara keikutsertaan Prolanis dengan tingkat efikasi diri pasien DM tipe 2 di Puskesmas 1 Kembaran. Metode: Penelitian analitik observasional dengan crosssectional, melibatkan 44 sampel pasien DM tipe 2 yang terdaftar Prolanis dengan simple random sampling, analisis data menggunakan uji korelasi Spearman. Hasil: Hasil penelitian menunjukkan dari 44 responden didapatkan distribusi karakteristik responden didominasi oleh responden dengan usia kategori lansia akhir 52,3\%, jenis kelamin perempuan 84,1\%, tingkat pendidikan SD 59\%, dan tidak bekerja 36,4\%. Responden yang mengikuti Prolanis dengan tingkat efikasi diri rendah sebanyak 7\%, dengan tingkat efikasi diri sedang 7\%, dan dengan tingkat efikasi diri tinggi $86 \%$. Hasil uji korelasi spearman menunjukan terdapat hubungan yang signifikan antara keikutsertaan Prolanis dengan tingkat efikasi diri pasien DM tipe 2 di Puskesmas 1 Kembaran dengan $\mathrm{P}$ value $0,000(\mathrm{P}=<0,05)$. Kesimpulan: Terdapat hubungan yang signifikan antara keikutsertaan Prolanis dengan tingkat efikasi diri pasien Diabetes Mellitus tipe 2 di Puskesmas 1 Kembaran.

Kata kunci: Tingkat Efikasi Diri, Prolanis, Diabates Mellitus tipe 2.

\section{PENDAHULUAN}

IDF atau International Diabetes Federation melaporkan terdapat sekitar 382 juta orang yang terdiagnosis dengan Diabetes Mellitus (DM) di dunia pada tahun 2013 dan diprediksi meningkat setiap tahunnya. Penderita penyakit DM di Indonesia diperkirakan meningkat menjadi 10 juta orang pada tahun 2015 dan termasuk dalam penyebab kematian utama di Indonesia (1).

Data Sample Registration Survey tahun 2014 menunjukkan bahwa DM menduduki peringkat ke-3 sebagai penyebab kematian terbesar di Indonesia $(6,7 \%)$, setelah stroke dan penyakit jantung koroner. Hal ini menjadikan DM sebagai prioritas utama pengendalian penyakit kronis di Jawa Tengah. Berdasarkan data survei pendahuluan di Dinas Kesehatan Kabupaten Banyumas, prevalensi tertinggi DM tipe 2 di Kabupaten Banyumas terdapat di Puskesmas 1 Kembaran dengan 1233 kasus pada tahun 2017 (1).

DM merupakan penyakit kronis yang ditandai dengan kegagalan tubuh untu menghasilkan hormon insulin yang disebabkan adanya kelainan sekresi insulin, kerja insulin atau kedua-duanya yang ditandai dengan meningkatnya kadar glukosa dalam darah yang melewati batas normal. DM diklasifikasi menjadi DM tipe 1 dan DM tipe 2 tergantung dari sebab gangguan kinerja insulinnya (2).

Penyakit DM membutuhkan perhatian dan perawatan medis dalam waktu lama, baik untuk mencegah komplikasi maupun perawatan sakitnya. Pengendalian DM sangat penting dilaksanakan sedini mungkin, untuk menghindari biaya pengobatan yang sangat mahal. DM yang tidak segera ditangani dapat menyebabkan disabilitas, penurunan produktivitas dan kematian dini. DM dan komplikasinya membawa kerugian ekonomi yang besar bagi penderita, keluarga, dan negara. Masalah yang sering ditemukan di Indonesia terkait DM antara lain tidak meratanya populasi penderita DM yang mendapatkan akses pusat pelayanan kesehatan yang mimpuni serta keterbatasan sarana/prasarana penanganan kasus DM (3).

Dalam penanganan DM tipe 2, pemerintah melalui BPJS Kesehatan membentuk Program Pengelolaan Penyakit Kronis (Prolanis). Prolanis merupakan sistem pelayanan kesehatan dengan pendekatan proaktif yang secara bersamaan 
melibatkan peserta, fasilitas kesehaan, serta BPJS. Tujuan program ini adalah untuk mencapai kulaitas hidup yang optimal bagi peserta BPJS Kesehatan melalui pembiayaan yang lebih efisien (4).

Kegiatan Prolanis diharapkan mampu meningkatkan efikasi diri penderita DM tipe 2 dalam kepatuhan perawatan penyakitnya. Efikasi diri adalah keyakinan individu mengenai kemampuannya dalam menyelesaikan tugas yang diperlukan untuk mencapai hasil tertentu (5).

Efikasi diri pada pasien DM tipe 2 berfokus kepada seberapa besar keyakinan diri pasien untuk dapat melakukan perilaku agar mendukung peningkatan status kesehatan pengelolaan perawatan diri seperti pola makan, aktivitas fisik, medikasi, perawatan kaki, serta kontrol glukosa darah. Efikasi diri terdiri dari beberapa dimensi yang dapat diukur, antara lain magnitude (tingkat kesulitan), strength (kekuatan) dan generality (generalitas). Tingkat kepercayaan diri dalam perawatan DM tipe 2 dinilai dengan kepatuhan pasien untuk melakukan aktivitas fisik, diet, dan pemantauan glukosa (6).

Berdasarkan data yang diperoleh dari survei pendahuluan di Dinas Kesehatan Kabupaten Banyumas jumlah penderita DM tipe 2 yang mengikuti kegiatan Prolanis hanya 79 orang, terhitung dari bulan Januari 2016. Tingginya kasus yang ada, berbanding terbalik dengan jumlah peserta Prolanis yang masih sedikit. Oleh karena itu, untuk menekan tingginya prevalensi DM tipe 2 dan meningkatkan kesadaran masyarakat mengenai pentingnya Prolanis, perlu dilakukan penelitian mengenai apakah terdapat hubungan antara keikutsertaan Prolanis dengan tingkat efikasi diri pasien Diabetes Mellitus tipe 2.

\section{METODE}

Penelitian ini adalah observasional analitik dengan rancangan penelitian cross sectional. Populasi dari penelitian ini adalah pasien DM tipe 2 yang terdaftar Prolanis di Puskesmas 1 Kembaran. Teknik sampling yang digunakan yaitu simple random sampling dan besar sampel diperoleh dari rumus Slovin sebanyak 44 responden.

Variabel keikutsertaan Prolanis dalam penelitian ini diketahui dari data rekam medis peserta Prolanis yang diperoleh dari Puskesmas dan tingkat efikasi diri diukur mengunakan kuesioner efikasi diri berupa Diabetes Management Self-Efficacy Scale (DMSES). DMSES terdiri dari 15 pertanyaan (7). Hasil kuisioner tersebut kemudian di analisis dengan uji korelasi Spearman. 
HASIL

Analisa Univariat Distribusi Responden Berdasarkan Karakteristik Responden

Tabel 1. Distribusi Responden

\begin{tabular}{|c|c|c|}
\hline \multirow[t]{2}{*}{ Karakteristik } & \multicolumn{2}{|c|}{ Responden } \\
\hline & Frekuensi (n) & Persen (\%) \\
\hline \multicolumn{3}{|c|}{ - } \\
\hline Lansia Awal & 8 & 18.2 \\
\hline Lansia Akhir & 23 & 52.3 \\
\hline Masa Manula & 13 & 29.5 \\
\hline Total & 44 & 100.0 \\
\hline \multicolumn{3}{|l|}{ Jenis Kelamin } \\
\hline Laki-laki & 7 & 15.9 \\
\hline Perempuan & 37 & 84.1 \\
\hline Total & 44 & 100.0 \\
\hline \multicolumn{3}{|l|}{ Pendidikan } \\
\hline $\begin{array}{l}\text { Tidak } \\
\text { Sekolah }\end{array}$ & 5 & 11.4 \\
\hline SD & 26 & 59.1 \\
\hline SMP & 7 & 15.9 \\
\hline SMA & 3 & 6.8 \\
\hline $\mathrm{PT}$ & 3 & 6.8 \\
\hline Total & 44 & 100.0 \\
\hline \multicolumn{3}{|l|}{ Pekerjaan } \\
\hline $\begin{array}{l}\text { Tidak } \\
\text { Bekerja }\end{array}$ & 16 & 36.4 \\
\hline IRT & 13 & 29.5 \\
\hline Petani & 8 & 18.2 \\
\hline Pedagang & 4 & 9.1 \\
\hline $\begin{array}{l}\text { PNS/ } \\
\text { Pensiunan }\end{array}$ & 3 & 6.8 \\
\hline Total & 44 & 100.0 \\
\hline
\end{tabular}

Distribusi karakteristik responden didominasi oleh responden dengan usia kategori lansia akhir 52,3\%, jenis kelamin perempuan $84,1 \%$, tingkat pendidikan SD $59 \%$, dan tidak bekerja $36,4 \%$.

\section{Pasien DM tipe 2 yang terdaftar Prolanis di Puskesmas I Kembaran}

Tabel 2. Pasien DM Tipe 2 yang Terdaftar Prolanis di Puskesmas 1 Kembaran

\begin{tabular}{ccc}
\hline $\begin{array}{c}\text { Pasien DM tipe } \\
\text { 2 (Prolanis) }\end{array}$ & $\begin{array}{c}\text { Frekuensi } \\
(\mathbf{n})\end{array}$ & $\begin{array}{c}\text { Presentasi } \\
(\mathbf{\%})\end{array}$ \\
\hline Iya & 78 & $6 \%$ \\
Tidak & 1155 & $94 \%$ \\
Total & 1233 & 100 \\
\hline
\end{tabular}

Sumber: Dinas Kesehatan Kabupaten Banyumas, 2018.
Pasien DM tipe 2 di Puskesmas 1 Kembaran yang terdaftar Prolanis sejak tahun 2016 - 2018 yaitu sebanyak 79 orang (6\%), sedangkan yang tidak terdaftar Prolanis sebanyak 1154 orang (94\%). Tingginya kasus DM tipe 2 yang ada, berbanding terbalik dengan jumlah peserta Prolanis yang masih sedikit.

\section{Tingkat Efikasi Diri Pasien DM Tipe 2 di Puskesmas 1 Kembaran}

Tabel 3. Tingkat Efikasi Diri Pasien DM tipe 2 di Puskesmas 1 Kembaran

\begin{tabular}{cccc}
\hline $\begin{array}{c}\text { Tingkat } \\
\text { Efikasi } \\
\text { Diri }\end{array}$ & Rendah & Sedang & Tinggi \\
\hline $\begin{array}{c}\text { Tingkat } \\
\text { efikasi } \\
\text { diri }\end{array}$ & 3 & 3 & 38 \\
\hline
\end{tabular}

Hasil penelitian menunjukkan pasien DM tipe 2 peserta Prolanis yang memiliki tingkat efikasi diri rendah sebanyak $7 \%$, memiliki tingkat efikasi diri sedang sebanyak $7 \%$, dan memiliki tingkat efikasi diri tinggi sebanyak $86 \%$.

\section{Uji Normalitas}

Tabel 4. Tingkat Efikasi Diri Pasien DM tipe 2 di Puskesmas 1 Kembaran

\begin{tabular}{lcccccc}
\hline & \multicolumn{3}{c}{ Kolmogorov- } & \multicolumn{3}{c}{ Shapiro-Wilk } \\
& Stat & df & Sig. & Stat & df & Sig. \\
\cline { 2 - 7 } & .334 & 44 & .000 & .696 & 44 & .000 \\
$\begin{array}{l}\text { Keikutsertaan } \\
\text { Prolanis } \\
\begin{array}{l}\text { Tingkat } \\
\text { Efikasi Diri }\end{array}\end{array}$ & .497 & 44 & .000 & .451 & 44 & .000 \\
\hline
\end{tabular}

Hasil uji normalitas menggunakan uji Shapiro wilk $(\mathrm{n}<50)$, diperoleh nilai signifikansi $\mathrm{p}=0.000(\mathrm{p}<0.05)$, maka data dinyatakan tidak terdistribusi normal. Uji korelasi dilakukan menggunakan uji non parametrik Spearman. 
Uji Hipotesis

Tabel 5. Hubungan Keikutsertaan Prolanis dengan Tingkat Efikasi Diri Pasien DM tipe 2 di Puskesmas I Kembaran

\begin{tabular}{|c|c|c|c|c|}
\hline & & & $\begin{array}{l}\text { Keikut- } \\
\text { sertaan } \\
\text { Prolanis }\end{array}$ & $\begin{array}{c}\text { Tingkat } \\
\text { efikasi } \\
\text { diri }\end{array}$ \\
\hline \multirow{8}{*}{$\begin{array}{c}\text { Spear- } \\
\text { man's } \\
\text { rho }\end{array}$} & & Correlation & 1.000 & $.637 * *$ \\
\hline & Keikuts & Coefficient & & \\
\hline & $\begin{array}{l}\text { ertaan } \\
\text { Prolanis }\end{array}$ & $\begin{array}{c}\text { Sig. (2- } \\
\text { tailed) }\end{array}$ & . & .000 \\
\hline & & $\mathrm{n}$ & 44 & 44 \\
\hline & & Correlation & $.637 * *$ & 1.000 \\
\hline & Tingkat & Coefficient & & \\
\hline & $\begin{array}{l}\text { efikasi } \\
\text { diri }\end{array}$ & $\begin{array}{l}\text { Sig. (2- } \\
\text { tailed) }\end{array}$ & .000 & . \\
\hline & & $\mathrm{n}$ & 44 & 44 \\
\hline
\end{tabular}

Hasil uji spearman rank menunjukkan bahwa terdapat hubungan antara keikutsertaan Prolanis dengan tingkat efikasi diri. Arah hubungan adalah positif menunjukkan bahwa dengan keikutsertaan Prolanis akan semakin meningkatkan efikasi diri, dengan interpretasi hubungan adalah kuat.

\section{PEMBAHASAN}

Berdasarkan hasil penelitian yang telah dilakukan, hasil analisis korelasi spearman menunjukkan adanya hubungan yang signifikan antara keikutsertaan Prolanis dengan tingkat efikasi diri pasien Diabetes Mellitus tipe 2 di Puskesmas 1 Kembaran. Arah hubungan adalah positif menunjukkan bahwa dengan keikutsertaan Prolanis akan semakin meningkatkan efikasi diri dengan interpretasi hubungan adalah kuat.

Hasil penelitian menunjukkan pasien DM tipe 2 peserta Prolanis yang memiliki tingkat efikasi diri rendah sebanyak $7 \%$, memiliki tingkat efikasi diri sedang sebanyak 7\%, dan memiliki tingkat efikasi diri tinggi sebanyak $86 \%$. Sebagian besar peserta Prolanis penyandang DM tipe $2 \mathrm{di}$ Puskesmas 1 Kembaran memiliki tingkat efikasi diri yang tinggi.
Fokus efikasi diri pasien DM tipe 2 adalah keyakinan pasien untuk mampu melakukan perilaku yang dapat mendukung perbaikan penyakitnya dan meningkatkan pengelolaan perawatan diri meliputi pola makan, latihan fisik, obat-obatan, perawatan kaki, dan kontrol kadar glukosa. Tingginya tingkat efikasi diri menandakan bahwa seseorang sudah mampu mengelola penyakitnya dengan baik. Tingkat efikasi diri yang tinggi dalam mengelola penyakitnya dapat disebabkan karena kegiatan Prolanis yang meliputi kegiatan edukasi dan konsultasi medis, kunjungan rumah, aktivitas kelompok, monitor status kesehatan, serta pembagian obat secara berkala sudah terlaksana dengan baik (5).

Sebagian besar peserta Prolanis penyandang DM tipe 2 di Puskesmas 1 Kembaran memiliki tingkat efikasi diri yang tinggi. Hal ini menunjukkan bahwa kegiatan Prolanis yang dilakukan sudah mencapai tujuan dan manfaatnya. Pengelolaan penyakit iini memerlukan waktu lama, sehingga membutuhkan perubahan perilaku. Efikasi diri dapat memengaruhi komitmen pasien terkait kepatuhan pasien dalam pengelolaan penyakitnya. Tingkat efikasi diri yang rendah dapat menyebabkan ketidakpatuhan pada pasien, sehingga berdampak terhadap meningkatnya morbiditas dan mortalitas, serta menurunnya kualitas hidup. Berdasarkan hasil yang telah diperoleh, terbukti bahwa kegiatan Prolanis mampu meningkatkan efikasi diri penderita DM tipe 2 dalam kepatuhan perawatan penyakitnya (8).

Kegiatan Prolanis yang sudah terlaksana dengan baik mampu meningkatkan kesadaran dan tingkat efikasi diri pasien dalam mengelola penyakitnya. Bentuk kegiatan Prolanis di Puskesmas 1 Kembaran seperti kegiatan pendidikan 
kesehatan serta konsultasi medis dilakukan oleh satu kali setiap bulannya oleh Dokter, monitoring status kesehatan satu kali dalam satu bulan, kegiatan fisik seperti senam dilakukan satu kali dalam satu minggu, pelayanan medikasi oleh dokter, kegiatan pengingat melalui sms gateway yang dilakukan oleh pengelola Prolanis sedangkan untuk kegiatan home visit belum terlaksana. Dengan aktivitas tersebut diharapkan mampu mencapai target dalam pemeriksaan DM dari 4 (empat) indikator yaitu: indeks massa tubuh (IMT) (18.5-25), glukosa darah puasa (80- $100 \mathrm{mg} / \mathrm{dl})$, glukosa darah post prandial (70-140 mg/dl), dan HbA1C (4.8-5.9\%) (9).

\section{KESIMPULAN}

Tingkat efikasi diri pasien Diabetes Mellitus tipe 2 di Puskesmas 1 Kembaran sebagian besar berada ditingkat efikasi diri tinggi. Terdapat hubungan yang signifikan antara keikutsertaan Prolanis dengan tingkat efikasi diri pasien Diabetes Mellitus tipe 2 di Puskesmas 1 Kembaran. Hasil penelitian ini diharapkan dapat menjadi landasan implementasi kepada masyarakat, untuk memberikan edukasi ataupun penyuluhan tentang pentingnya kegiatan Prolanis untuk mengelola penyakit kronis dan mencegah terjadinya komplikasi yang dapat terjadi.

\section{UCAPAN TERIMAKASIH}

Terimakasih penulis haturkan kepada Fakultas Kedokteran UMP, Dinas Kesehatan Kabupaten Banyumas, Puskesmas 1 Kembaran, dan seluruh pihak yang telah mendukung dan membantu penelitian ini.

\section{KONFLIK KEPENTINGAN}

Penulis menyatakan tidak terdapat konflik kepentingan diantara penulis maupun afiliasi, dan sebagainya.

\section{REFERENSI}

1. Kemenkes RI. Kenali faktor risiko diabetes secara dini dan jalankan pola hidup sehat. Kementerian Kesehatan Republik Indonesia. 2016. p. 2015-6.

2. Price, S. A. dan Wilson LM. Patofisiologi : Konsep Klinis ProsesProses Penyakit. Vol. 1. Jakarta: EGC; 2006.

3. PERKENI. Konsensus Pengendalian dan Pencegahan Diabetes Melitus Tipe 2 di Indonesia 2015. Perkeni. 2015. 78 p.

4. BPJS. Panduan praktis Prolanis (Program pengelolaan penyakit kronis). BPJS Kesehat. 2014;3-6.

5. Abubakari A-R, Cousins R, Thomas C, Sharma D, Naderali EK. Sociodemographic and Clinical Predictors of Self-Management among People with Poorly Controlled Type 1 and Type 2 Diabetes: The Role of Illness Perceptions and Self-Efficacy. J Diabetes Res. 2016;2016:1-12.

6. Hernandez R, Ruggiero L, Prohaska TR, Chavez N, Boughton SW, Peacock N, et al. A Cross-sectional Study of Depressive Symptoms and Diabetes Self-Care in African Americans and Hispanics/Latinos with Diabetes: The Role of Selfefficacy. Diabetes Educ. 2016;42(4):452-61.

7. Fappa E, Efthymiou V, Landis G, Rentoumis A, Doupis J. Validation of the Greek Version of the Diabetes Management Self-Efficacy Scale (GR-DMSES). Adv Ther [Internet]. 
2016 Jan 21;33(1):82-95. Available from:

http://link.springer.com/10.1007/s12 325-015-0278-1

8. Rahman HF, Yulia Y, Sukmarini L.

Efikasi Diri, Kepatuhan, dan

Kualitas Hidup Pasien Diabetes

Melitus Tipe 2 (Self Efficacy, Adherence, and Quality of Life of Patients with Type 2 Diabetes). J Pustaka Kesehat [Internet]. 2017 Feb 7;5(1):108-13. Available from: https://jurnal.unej.ac.id/index.php/J PK/article/view/4059

9. Sitompul S, Suryawati C, Wigati PA. Analisis Pelaksanaan Program Pengelolaan Penyakit Kronis (Prolanis) BPJS Kesehatan pada Dokter Keluarga di Kabupaten Pekalongan Tahun 2016. J Kesehat Masy [Internet]. 2016 Nov 1;4(4):145-53. Available from: https://ejournal3.undip.ac.id/index.p hp/jkm/article/view/13952 